\title{
Pengaruh Thinking Maps dalam Pembelajaran Berbasis Masalah terhadap Penguasaan Konsep Siswa
}

\author{
Devis Yusofa ${ }^{1}$, Lia Yuliati ${ }^{1}$, Muhardjito ${ }^{1}$ \\ ${ }^{1}$ Pendidikan Fisika-Universitas Negeri Malang
}

\begin{tabular}{l}
\hline \hline INFO ARTIKEL \\
\hline Riwayat Artikel: \\
Diterima: 05-12-2018 \\
Disetujui: $17-01-2019$ \\
\hline
\end{tabular}

\section{Kata kunci:}

thinking maps; problem based learning; concept achievement; pembelajaran berbasis masalah; penguasaan konsep

\section{ABSTRAK}

Abstract: This research was aimed to determine the differences in concept achievement of students who learn using Thinking maps in Problem Based learning with students who learn to use Problem Based learning and conventional learning. This research is quasi experiment researches with posttest only control group design. The research was conducted in SMAN 1 Singosari on class X academic year 2016/2017. Data collection obtained from concept achievement test. Test to determine the difference between the three treatment classes was done by MANOVA test. The result of the research shows that there is influence of Thinking Maps in Problem Based learning on Concept Achievement of Student. These results are reinforced by the data of M.A.PP.E.R which shows that the higher the level of Thinking Maps made the student's concepts achievemenis getting better.

\begin{abstract}
Abstrak: Penelitian ini bertujuan untuk mengetahui perbedaan penguasaan konsep dan kemampuan pemecahan masalah antara siswa yang belajar menggunakan Thinking maps dalam pembelajaran berbasis masalah, pembelajaran berbasis masalah dan pembelajaran konvensional. Penelitian ini merupakan penelitian kuasi eksperimen dengan desain posttest only control group design. Penelitian dilaksanakan di SMAN 1 Singosari pada siswa kelas X tahun ajaran 2016/2017. Pengumpulan data menggunakan instrumen soal penguasaan konsep. Uji statistik MANOVA digunakan untuk mengetahui perbedaan penguasaan konsep. Hasil penelitian diperoleh terdapat pengaruh Thinking maps dalam pembelajaran berbasis masalah terhadap penguasaan konsep. Hasil ini diperkuat oleh data M.A.PP.E.R yang menunjukkan bahwa semakin tinggi tingkat hasil Thinking maps penguasaan konsep siswa semakin baik.
\end{abstract}

\section{Alamat Korespondensi:}

Devis Yusofa

Pendidikan Fisika

Universitas Negeri Malang

Jalan Semarang 5 Malang

E-mail: devisyusofapasca@gmail.com

Pembelajaran Fisika membutuhkan penguasaan konsep yang baik dari siswa sebagai acuan untuk memecahkan masalah dalam pembelajaran Fisika (Silaban, 2014). Penguasaan konsep siswa merupakan dasar siswa untuk memahami permasalahanpermasalahan dalam Fisika (Suminten, 2015). Penguasaan konsep merupakan salah satu aspek dalam mengukur kemampuan belajar siswa guna mewujudkan pembelajaran yang berkualitas (Doyan \& Sukmantara, 2014). Penguasaan konsep siswa sangat penting dimiliki oleh setiap individu. Hal ini dikarenakan penguasan konsep dapat bermanfaat dan meningkatkan kemampuan memecahkan suatu masalah dalam kehidupan sehari-hari (Silaban, 2014). Pengusaan Konsep sangat penting dikuasai agar mampu berkomunikasi, menyampaikan pendapat, dan mengklasifikasi ide, gagasan atau peristiwa yang dialami dalam kehidupan sehari-hari (Suranti et al, 2016). Penguasaan konsep merupakan faktor penentu keberhasilan siswa dalam memecahkan masalah (Boujaoude \& Barakat, 2003).

Penguasaan konsep siswa SMA masih banyak mengalami kendala terutama pada materi impuls dan momentum. Kendala ini diantaranya kesulitan memahami konsep dan membangun suatu pengetahuan sehingga terjadi miskonsepsi (Remziye, 2013), kesulitan menentukan hubungan antar konsep impuls dan momentum (Gaigher et al. , 2007), dan siswa tidak dapat menjelaskan permasalahan impuls dan momentum dalam kehidupan sehari-hari (Dalaklioglu et al., 2015). Salah satu pembelajaran yang dapat membantu menyelesaikan masalah tersebut dan meningkatkan penguasaan konsep siswa adalah pembelajaran kolaboratif yang berfokus pada siswa.

Salah satu model pembelajaran kolaboratif yang dapat meningkatkan penguasaan konsep dan solusi dari kendala penelitian sebelumnya adalah Pembelajaran Berbasis Masalah. Pembelajaran Berbasis Masalah dapat meningkatkan penguasaan konsep siswa dalam pembelajaran Fisika (Tasoglu \& Bakac, 2014). Pembelajaran Berbasis Masalah dapat membantu siswa memiliki penguasaan konsep yang lebih baik (Saglam, 2010). Hasil pencapaian akademik pada beberapa konsep Fisika lebih tinggi pada siswa yang belajar menggunakan pembelajaran berbasis masalah (Polanco et al., 2004). Penerapan pembelajaran berbasis masalah dengan pendekatan inkuiri dapat meningkatkan penguasaan konsep elastisitas pada kategori sedang dan tinggi 
(Usnayati \& Prima, 2011). Namun, pembelajaran berbasis masalah saja masih belum cukup untuk meningkatkan penguasaan konsep secara maksimal. Hal ini dikarenakan banyak terdapat konsep abstrak saat mempelajari fisika (Selcuk, 2010). Untuk mengatasi permasalahan digunakan strategi tambahan yaitu dengan memasukkan strategi Thinking Maps pada Sintaks Pembelajaran Berbasis Masalah. Manfaat pembuatan Thinking Maps adalah untuk membantu siswa menentukan hubungan yang bermakna antara konsep yang dipelajari (Long \& Carlson, 2011). Penggunaaan Thinking Maps dalam pembelajaran pembelajaran memengaruhi perubahan penguasaan konsep siswa. Thinking Maps mengajak siswa berpikir kritis sehingga memengaruhi penguasaan konsep dan meningkatkan kemampuan pemecahan masalah (Long \& Carlson, 2011).

Thinking Maps dalam pembelajaran berbasis masalah akan membantu siswa dalam belajar. Pembelajaran berbasis masalah adalah pembelajaran yang memberikan siswa pengalaman menghadapi masalah yang otentik dan didesain untuk membantu mengembangkan kemampuan berpikir, kemampuan pemecahan masalah dan intelektual siswa; mempelajari peran menjadi orang dewasa dan mengembangkan kemampuan sosial melalui pengalaman dalam situasi nyata maupun simulasi; dan membuat siswa menjadi pelajar yang independen (Arends, 2012). Thinking Maps adalah bahasa atau media yang berupa alur bepikir yang diungkapkan secara spesifik melalui delapan proses kognitif yang saling terkait (Arends, 2012).

Pembelajaran Berbasis Masalah dan Thinking Maps merupakan model dan metode pembelajaran yang mampu meningkatkan kemampuan siswa dalam pembelajaran terutama penguasaan konsep siswa. Penggunaan Thinking maps akan membuat siswa lebih mudah dalam menyelesaikan masalah (Long \& Carlson, 2011). Hal ini menunjukkan bahwa Thinking Maps dapat membantu pembelajaran berbasis masalah terutama pada saat siswa memecahkan masalah dalam pembelajaran. Selain itu, siswa akan dapat memperluas kemampuan berpikir kritis dan meningkatkan pemahaman konsep yang mereka pelajari (Long \& Carlson, 2011). Pembelajaran Berbasis Masalah berbantuan Thinking Maps membantu siswa meningkatkan kemampuan pemecahan masalah siswa. Dapat dikatakan bahwa Thinking Maps dalam Pembelajaran Berbasis Masalah memberikan dampak positif dalam kegiatan pembelajaran.

\section{METODE}

Penelitian ini merupakan penelitian kuasi eksperimen dengan desain posttest only control group design. Penelitian ini menggunakan tiga kelas penelitian yaitu kelas pertama menggunakan Thinking maps dalam pembelajaran berbasis masalah dan kelas kedua menggunakan pembelajaran berbasis masalah dan kelas ketiga menggunakan pembelajaran konvensionalPenelitian dilaksanakan di SMAN 1 Singosari dan dilakukan pada populasi yang memiliki ciri yang sama atau homogen yaitu siswa kelas $\mathrm{X}$ tahun ajaran 2016/2017. Sampel dipilih dengan menggunakan teknik cluster sampling. Ketiga kelas penelitian yang terpilih memiliki jumlah siswa yang sama yaitu 38 siswa pada setiap kelas. Instrumen penelitian yang digunakan adalah instrumen perlakuan dan instrumen pengukuran. Instrumen perlakuan, meliputi silabus, RPP, dan LKS yang dibuat berdasarkan K.D 3.1. Instrumen pengukuran yang digunakan adalah tes penguasaan konsep berjumlah 15 soal dan tes kemampuan pemecahan masalah berjumlah sembilan soal yang dibuat berdasarkan indikator penguasaan konsep dan kemampuan pemecahan masalah.

Pengumpulan data dilakukan dalam tiga tahap yaitu tahap persiapan, tahap pelaksanaan, dan tahap pasca pelaksanaan. Tahap persiapan dilakukan secara urut dari observasi, menyusun perangkat, melakukan validitas instrumen, analisis hasil validitas, dan melakukan uji empiris instrumen soal. Tahap pelaksanaan yang dilakukan yaitu menentukan kelas penelitian eksperimen dan kontrol, memberi perlakuan berdasarkan kelas, melakukan observasi kegiatan pembelajaran, dan pemberian tes penguasaan konsep dan kemampuan pemecahan masalah. Tahap pasca pelaksanaan yang dilakukan setelah tahap pelaksanaan yaitu menganalisis data hasil tes penguasaan konsep dan kemampuan pemecahan masalah kemudian membuat laporan hasil penelitian. Data hasil Thinking Map diperoleh melalui indikator pada M.A.PP.E.R. yang terdiri dari lima kategori (Minimum, Attending, Participating, Effective, dan Reflective). Lima kategori ini mewakili kemampuan siswa dalam membuat Thinking Map. Data ini digunakan sebagai data pendukung hasil penelitian.

Analisis data dilakukan setelah tahap pelaksanaan pada hasil posttest siswa setiap kelas perlakuan untuk mengetahui perbedaan ketiga kelas perlakuan. Sebelum melakukan uji statistik perlu dilakukan uji prasyarat analisis yang menunjukkan data penelitian terdistribusi normal dan homogen. Uji statistik untuk mengetahui perbedaan ketiga kelas perlakuan menggunakan uji MANOVA. Uji Manova merupakan teknik statistik yang digunakan untuk menghitung uji signfikansi perbedaan rata-rata secara bersamaan antara kelompok untuk dua atau lebih variabel yang memiliki skala interval atau rasio. Uji Statistik MANOVA ini menggunakan taraf kepercayaan 95\% yang artinya jika signifikasi kurang dari 0,05 maka dapat dikatakan bahwa terdapat perbedaan penguasaan konsep dari ketiga kelas perlakuan. Setelah melakukan uji MANOVA dilakukan uji lanjut Tukey untuk membandingkan seluruh pasangan rata-rata kelas perlakuan. Hal ini dilakukan untuk mengetahui kelas mana yang memiliki perbedaan signifikan dengan kelas lain. Uji Lanjut Tukey digunakan karena jumlah siswa pada setiap kelas sama yaitu 38 siswa. 
HASIL

Data penguasaan konsep yang didapat dari penelitian berupa hasil posttest yang kemudian dirata-rata untuk melihat perbandingan nilai penguasaan konsep. Berikut nilai rata-rata posttest penguasaan konsep (Gambar 1).

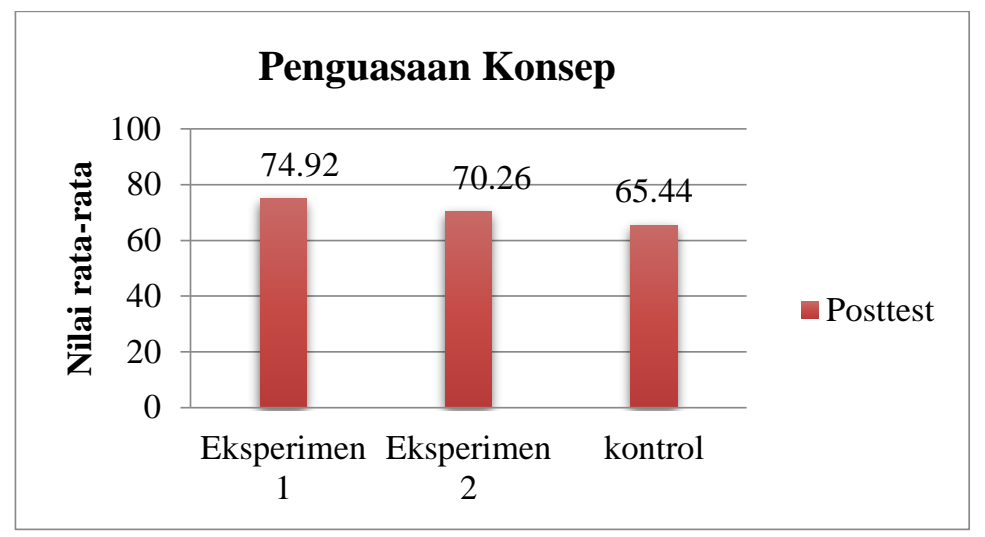

\section{Gambar 1. Diagram Perbandingan Nilai Rata-Rata Pretest dan Posttest Tes Prestasi Belajar}

Berdasarkan Gambar 1 diperoleh bahwa terdapat perbedaan penguasaan konsep pada ketiga kelas perlakuan. Terlihat bahwa nilai rata-rata kelas eksperimen yang belajar menggunakan strategi Thinking maps dalam pembelajaran berbasis masalah lebih baik jika dibandingkan dengan kelas eksperimen yang belajar menggunakan pembelajaran berbasis masalah dan kelas kontrol yang belajar menggunakan pembelajaran konvensional. Untuk menunjukkan perbedaan secara signifikan menggunakan uji MANOVA satu jalur. Hasil uji prasyarat menunjukkan bahwa data terdistribusi normal dan homogen. Sehingga dapat dilakukan uji MANOVA untuk mengetahui perbedaan dari antara kelompok yang berbeda. Jika nilai signifikansi kurang dari 0,05 pada taraf signifikansi $5 \%$, artinya terdapat perbedaan simultan dari beberapa variabel terikat antara kelompok yang berbeda.

Tabel 1. Hasil Uji Manova

\begin{tabular}{lllllll}
\hline \multicolumn{1}{c}{ Effect } & Value & $\boldsymbol{F}$ & Hypothesis $\boldsymbol{d f}$ & Error df & Sig. \\
\hline Intercept & Wilks' Lambda & .024 & $2.239 \mathrm{E3}^{\mathrm{a}}$ & 2.000 & 110.000 & .000 \\
& & & & & & \\
Kelas Perlakuan & Wilks' Lambda & .908 & $2,709^{\mathrm{a}}$ & 4.000 & 220.000 & .031 \\
\hline
\end{tabular}

Berdasarkan Tabel 1 didapatkan perbedaan antara strategi Thinking Maps dalam pembelajaran berbasis masalah dan pembelajaran konvensional terhadap penguasaan konsep siswa. Pada Test of Between-Subjects atau analisis secara terpisah pada data penguasaan diperoleh harga $\mathrm{F}$ sebesar 5,568 dengan signifikansi 0,05 lebih kecil dari 0,05. Hal ini menunjukkan bahwa terdapat perbedaan penguasaan konsep siswa karena perbedaan model pembelajaran. Dengan demikan, dapat dikatakan terdapat perbedaan penguasaan konsep siswa yang belajar melalui strategi Thinking Maps dalam pembelajaran berbasis masalah dan siswa yang dibelajarkan melalui pembelajaran konvensional. Akan tetapi, pada uji lanjut Tukey perbedaan yang signifikan hanya terdapat pada kelas eksperimen I dengan kelas kontrol dengan signifikansi 0,03. Meskipun begitu jika dilihat dari nilai rata-rata siswa menunjukkan kelas eksperimen I lebih tinggi daripada kelas eksperimen II dan kelas kontrol.

Data hasil Thinking Maps yang diperoleh melalui indikator pada M.A.PP.E.R dibandingkan dengan data penguasaan konsep siswa. Data ini digunakan untuk mengetahui pengaruh Thinking Maps terhadap pembelajaran berbasis masalah pada kelas eksperimen. Dari data hasil M.A.PP.E.R didapatkan penguasaan konsep pada rentang nilai 53 sampai 67 termasuk kategori Attending, pada rentang nilai 67 sampai 87 termasuk kategori Participating, pada rentang nilai 73 sampai 93 termasuk kategori Effective, dan pada rentang nilai 80 sampai 93 termasuk kategori Reflective. Hasil ini menunjukkan semakin tinggi kategori siswa membuat Thinking Maps maka semakin tinggi penguasaan konsep siswa.

\section{PEMBAHASAN}

Nilai rata-rata penguasaan konsep pada siswa yang belajar menggunakan strategi Thinking Maps dalam pembelajaran berbasis masalah dan pembelajaran konvensional menunjukkan hasil yang berbeda. Siswa yang belajar dengan strategi Thinking Maps dalam pembelajaran berbasis masalah mendapatkan hasil posttest yang lebih baik dibandingkan kedua kelas perlakuan yang lain. Hasil observasi pada kelas Eksperimen I menunjukkan siswa yang belajar menggunakan Thinking Maps pada pembelajaran berbasis masalah lebih banyak bertanya dan senantiasa menunjukkan hasil karya mereka. Hasil pemecahan masalah yang ditunjukkan siswa lebih menunjukkan solusi yang tepat dan konsep yang sesuai. Beberapa hal ini dapat 
memengaruhi hasil akhir dan penguasaan konsep siswa. Hasil penelitian ini menunjukkan bahwa metode pembelajaran memberikan pengaruh terhadap hasil belajar sebagai faktor eksternal. Model pembelajaran berbasis masalah dapat meningkatkan kemampuan berpikir kritis dan penguasaan konsep siswa (Muslim et al., 2015). Hasil ini juga ditunjukkan berdasarkan pengamatan di kelas yang menunjukkan bahwa siswa yang belajar menggunakan Pembelajaran Berbasis Masalah menunjukkan perilaku yang berbeda dengan siswa yang belajar menggunakan pembelajaran konvensional saja.

Siswa pada pembelajaran berbasis masalah terlihat lebih antusias dalam pembelajaran dan tidak merasa bosan sampai akhir pembelajaran. Hal ini juga berbeda dengan kelas yang menggunakan Thinking Maps pada pembelajaran berbasis masalah. Pada kelas yang menggunakan Thinking Maps siswa lebih banyak bertanya dan senantiasa menunjukkan hasil karya mereka. Hasil pemecahan masalah yang ditunjukkan siswa pada kelas yang menggunakan Thinking Maps lebih menunjukkan solusi yang tepat dan menggunakan konsep yang sesuai sehingga dapat memengaruhi hasil akhir dan penguasaan konsep siswa. Hasil belajar siswa yang menggunakan Thinking Maps lebih tinggi daripada yang tidak menggunakan Thinking Maps. Penggunaan Thinking Maps memengaruhi penguasaan konsep siswa dalam kategori sedang (Armawan et al., 2017). Berdasarkan data yang didapatkan dalam penelitian menggunakan M.A.PP.E.R penggunaan Thinking Maps memengaruhi proses pembelajaran berbasis masalah sehingga terdapat perbedaan penguasaan konsep. Hal ini ditunjukkan dari hasil analisis bahwa semakin tinggi kategori siswa dalam pembuatan Thinking Maps semakin tinggi pula penguasaan konsep siswa.

\section{SIMPULAN}

Berdasarkan hasil penelitian dan pembahasan didapatkan kesimpulan bahwa terdapat perbedaan antara penguasaan konsep siswa yang belajar menggunakan strategi Thinking Maps dalam pembelajaran berbasis masalah dan siswa yang belajar dengan pembelajaran konvensional. Pembuatan tes untuk mengukur penguasaan konsep hendaknya memperhatikan dengan baik dan dikembangkan sesuai dengan $\mathrm{C} 1$ - C6 yang sudah ditetapkan. Hal ini bertujuan agar tes yang dibuat dapat benar-benar mengukur penguasaan konsep siswa dengan lebih baik. Selain itu, dalam penerapan strategi Thinking Maps harus ditempatkan pada sintaks pembelajaran yang tepat agar tidak mengganggu proses pembelajaran dan benar-benar bermanfaat dalam pembelajaran. Selain itu, penggunaan strategi Thinking Maps dalam model pembelajaran yang berbeda juga dibutuhkan sehingga hasil penelitian tersebut dapat menunjukkan peran Thinking Maps dalam setiap model pembelajaran.

\section{DAFTAR RUJUKAN}

Arends, R. I. (2012). Learning to Teach Ninth Edition (9th ed.). USA: McGraw-Hill.

Armawan, D., Parno., \& Yuliati, L. (2017). Analisis Strategi Thinking Maps dalam Pembelajaran Inkuiri Terbimbing terhadap Kemampuan Berpikir Kritis. Jurnal Pendidikan: Teori, Penelitian, dan Pengembangan, 2(5), 652-660.

Boujaoude, S., \& Barakat, H. (2003). Student' Problem Solving Strategies in Stoichiometry and Their Relationships to Conceptual Understanding and Learning Approaches. Electronic Journal of Science Education, 7(3).

Dalaklioglu, S., Demirci, N., \& Sekercioglu, A. (2015). Eleventh Grade Students Difficulties and Misconceptions About Enery and Momentum Concepts. International Journal on New Trends in Education and Their Implications, 6(1), 13-21.

Doyan, A., \& Sukmantara, I. K. Y. (2014). Pengembangan Web Intranet Fisika untuk Meningkatkan Penguasaan Konsep dan Kemampuan Pemecahan Masalah Siswa SMK. Jurnal Pendidikan Fisika Indonesia, 10(2), 117-127. DOI: 10.15294/jpfi.v10i2.3348

Gaigher, E., Rogan, J. M., \& Braun, M. W. H. (2007). Exploring the Develompent of Conceptual Understanding Through Structured Problem-Solving in Physics. International Journal of Science Education, 9(29), 1089-1110.

Long, D., \& Carlson, D. (2011). Mind The Map: How Thinking Maps Affect Student Achievement. An Online Journal for Teacher Researcher, 13(2), 262-272.

Muslim, I., Halim, A., \& Safitri, R. (2015). Penerapan Model Pembelajaran PBL untuk Meningkatkan Penguasaan Konsep dan Keterampilan Berpikir Kritis Siswa pada Konsep Elastisitas dan Hukum Hooke di SMA Negeri Unggul Harapan Persada. Jurnal Pendidikan Sains Indonesia, 3(2), 35-50.

Polanco, R., Calderón, P., \& Delgado, F. (2004). Effects of a Problem-Based Learning Program on Engineering Students' Academic Achievements in a Mexican University. Innovations in Education and Teaching International, 41(2), $145-155$.

Remziye, N. E. (2013). Momentum Concept in the Process of Knowledge Construction. Educational Sciences: Theory \& Practice, 13(3), 1897-1901.

Saglam, M. (2010). Students' Performance Awareness, Motivational Orientations and Learning Strategies in A Problem-Based Electromagnetism Course. Asia-Pacific Forum on Science Learning and Teaching, 11(1).

Selcuk, G. (2010). The Effects of Problem Based Learning on Pre-Service Teachers' Achievement, Approaches and Attitudes Towards Learning Physics. International Journal of the Physical Sciences, 5(6), 711-721.

Silaban, B. (2014). Hubungan Antara Penguasaan Konsep Fisika dan Kreativitas dengan Kemampuan Memecahkan Masalah pada Materi Pokok Listrik Statis. Jurnal Penelitian Bidang Pendidikan, 20(1), 65-75.

Suminten, N. (2015). Relating-Experiencing-Applying-Cooperating-Transferring (REACT) dengan Pendekatan Inkuiri untuk Mengurangi Miskonsepsi Fisika Siswa. Omega: Jurnal Fisika dan Pendidikan Fisika, 1(2), 6-10.

Suranti, Y., Gunawan, \& Sahidu, H. (2016). Pengaruh Model Project Based Learning Berbantuan Media Virtual terhadap Penguasaan Konsep Peserta didik pada Materi Alat-alat Optik. Jurnal Pendidikan Fisika dan Teknologi, 2(2), 73-79. 
Tasoglu, K., \& Bakac, M. (2014). The effect of Problem Based Learning Approach on Conceptual Understanding in Teaching of Magnetism Topics. Urasian J. Phys. \& Chem, 6(2), 110-122.

Usnayati, H., \& Prima, E. C. (2011). Penerapan Model Pembelajaran Problem Based Learning dengan Pendekatan Inkuiri untuk Meningkatkan Keterampilan Proses Sains dan Penguasaan Konsep Elastisitas pada Siswa SMA. In Prosiding Seminar Nasional Penelitian, Pendidikan dan Penerapan MIPA. Yogyakarta: Prosiding Seminar Fakultas MIPA, Universitas Negeri Yogyakarta. 